\title{
XXXI. ON THE PSYCHOLOGICAL RESPONSE TO UNKNOWN PROPER NAMES
}

\author{
By G. ENGLISH
}

In this paper we report some experiments which bear upon the nature of the psychological response to proper names of unknown persons. Kollarits, who was concerned with imagery only, ${ }^{1}$ found (I) that such imagery is conditioned upon some personal trait or characteristic, such as literary style, religious, political, professional life, etc.; or (2) that the image is that of a person of the same or a similar name, or (3) of the same nationality. He suspects other factors, however, and he requests the testimony of other observers. Claparède has responded with a suggestion which we shall consider later. The problem is of interest not only because it involves the imagery of imagination, but also because it has a bearing upon the psychology of meaning. We have substituted experimental conditions for the more or less casual observations of Kollarits, and we have further submitted the suggestion of Claparède to experiment.

I. We first prepared a series of names of distinguished psychologists, and presented each name to four men and three women students in an advanced course in systematic psychology. The names were familiar, but the great majority of the persons were unknown to all. We hoped in this series to obtain records of the habitual imagery, if such imagery existed, which represented the names. The procedure was as follows: The observer sat with eyes closed, and was given a warning signal before the name was presented. The stimuli were given auditorily. The observer was informed of the general nature of the experiment, and was told not to construct a visual image, but if one came to describe it as fully as possible. It was soon discovered, however, that some observers had no habitual visual imagery; and we therefore repeated the series with the instruction to report what the person named 'must look like.' We hoped by this second instruction to stimulate visual imagery in those observers with whom it was not habitual. This attempt was on the whole a failure; and we have therefore combined the results obtained from both instructions. We give them in numerical form in the following Table.

Memory image of

\section{TABle I}

The person as seen............................ 4

Picture (of the correct or of some other person) $\ldots \ldots \ldots \ldots \ldots$ I4

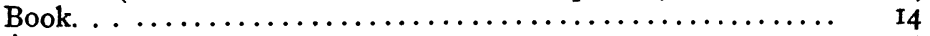

Apparatus. . . ............................... I3

Known persons (little or no connection) $\ldots \ldots \ldots \ldots \ldots \ldots \ldots$ I7

62

$1 \mathrm{~J}$. Kollarits. Observations de psychologie quotidienne, Arch. de psychol., XIV, 1914, 225-240. 
Imaginary images of the person (unanalysed) $\ldots \ldots \ldots \ldots \ldots$ I3

Picture and imaginary details............................... 9 Images derived from

Description of the person........................ 2

Facts known about the person. $\ldots \ldots \ldots \ldots \ldots \ldots \ldots \ldots \ldots \ldots \ldots \ldots$ ro

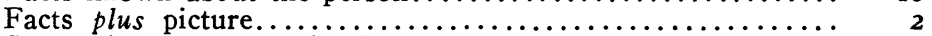

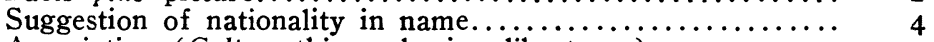

Association (Galton, thin and wiry, like tones) ............ I

Sugestion by meaning of word $($ Stout $) \ldots \ldots \ldots \ldots \ldots \ldots \ldots \ldots \ldots \ldots \ldots \ldots$ I

Suggestion by sound of word (Fechner, thin word, thin person) I

Name and literary style........................... I

Very vague imagery............................. 6

Scrappy images in an attempt to get imagery............. 3

Association to psychology...................... 2I

Verbal and miscellaneous associations........................... I9

Internal-speech repetitions or visual image of word......... 36

The results, when imagery was found, are quite similar to those of Kollarits. In only one-third of the cases, however, did visual imagery appear; in more than a third the associations were non-visual; and in many cases the proper name served only as a tag for a bit of apparatus or a book.

II. In the hope of avoiding memory-images and set meanings, we next selected from an English scientific journal a number of names which we thought would be entirely unfamiliar, but which should give the impression of actual names. Only one or two of the list proved to have been heard before, according to the observers' reports. Eleven observers, ten of them women, took part in the experiment; six of the eleven had had psychological training; the remainder were students specialising in literature. The series was given twice, under different instructions. Under the first, the observer was asked to report the mental processes which came involuntarily; under the second, he was asked to try to get an image of the person; if he could not, he was to say what the person 'would look like.' The second instruction yielded a larger number of visual images than the first; but qualitatively the results are so similar that we have for convenience combined them in the following Table.

Imagery of persons

TABLE 2

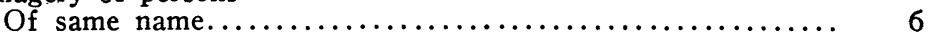

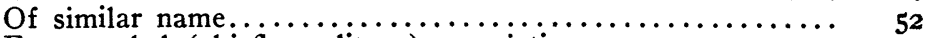

From verbal (chiefly auditory) association........................ 54

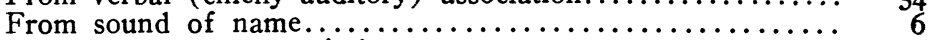

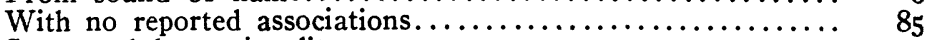

Suggested by nationality $\ldots \ldots \ldots \ldots \ldots \ldots \ldots \ldots \ldots \ldots \ldots \ldots \ldots \ldots, 7$

Enumeration of characteristics (no visual imagery) ........... 32

Verbal repetition (or nothing at all) ........................ 57

Verbal (chiefly auditory) associations $\ldots \ldots \ldots \ldots \ldots \ldots \ldots \ldots .87$

Miscellaneous. . . . . . . . . . . . . 23

Total number of cases of visual imagery.............. 210

Total number of cases of no visual imagery.............. 199 
In general these results are similar to those of the first series. There are, of course, practically no memory-images. There is a larger proportion of cases of visual imagery $(1 / 2$ as against $1 / 3)$, but there is still a large number of verbal reactions. The factors involved in the visual imagery are those which Kollarits has already pointed out. Only in six cases is there anything new: the images suggested by the sound of the name. A single image of this sort has been noted in Table $\mathrm{I}$.

III. This new result leads us to a consideration of the suggestion of Claparède noted above. He says: "The physiognomy of the proper name certainly plays a part. The sound of the name has an affective tone which co-operates in the elaboration of its mental representation. Other things equal, names consisting of heavy or repeated syllables call forth images of fat, heavy-set, bloated, or slightly ridiculous individuals; a short and sonorous name, on the other hand, suggests slender and active persons, etc. M. Patapoufard would evidently be of a type quite different from that of $M$. Flic. It is not without intention that Daudet has created the name of Tartarin, Dickens that of Pickrick, Flaubert those of Bouvard and of Pécuchet." The mental imagery aroused in these cases is not conditioned upon the individual circumstances and antecedents of the reader, "since these names produce a similar effect upon all readers."

In the six cases cited above, Klemm was reported as a "sharp word,' 'a thin word;' Ponsonby as 'a heavy word,' 'a ponderous name,' with 'a feeling of quick heaviness;' and Dendy as a 'thin, slight name.' In all these instances, as in that of Fechner in Table I, the visual imagery evoked was in Claparède's sense physiognomic. The cases are, however, few in number; and since it was possible that the names chosen for the experiment were not suitable to arouse associations of this sort, we devised two further experiments in order to test Claparède's contention. In the first we constructed fifty nonsense-names of one, two and three syllables; a large number of representative vowelsounds and consonant-combinations were put in a box, and the words were combined by chance. The names thus obtained were presented auditorily to eight observers; each name was pronounced three times over, the experimenter being careful to pronounce it slowly, distinctly, and (as nearly as possible) always in the same manner. As a check upon the auditory perception, the observer was asked to spell the word. He was further instructed to report his imagery or, in case visual imagery were wanting, to describe the person that "must belong to the name.' In the second experiment, pen-and-ink drawings selected from back numbers of Puck, and representing various types of individual, were mounted singly on white cardboards and used as stimuli. These pictures were presented one at a time to each of seven observers, all of whom had taken part in the preceding experiment. The instruction was as follows: "I shall show you the picture of a person. You are to name that person suitably; you are free to use real or nonsense names. After you have named the picture, you will be asked for introspections."

If we take the 500 reports as a whole, the results are negative. There is no constant or uniform tendency among these observers either to imagine a similar type of individual for the same name, or to furnish a similar type of name for the same picture. Individual differences among observers are great. In the nonsense-series one observer failed

$2 O p$. cit., $30 \mathrm{I} \mathrm{f}$. 
completely; he was able only to suggest a nationality to which the name might belong; and he did not complete the series. Of those remaining, five depended mainly upon auditory association; thus, the name Daw'thö suggested Delphos, doll, doddering and Daudy (a friend); and the images were a Greek man, a doll-like girl, an old woman, and a memory-image of a woman. The two remaining observers tended to furnish images corresponding with the sound, although they were not consistent. One of them had as an image for Daw'thö 'a heavily built, strong Greek, very jolly;' and said in his introspective report: "It seems as if the sounds aw and o, being generous sounds, should go with broad shoulders and perhaps good nature." In only five cases was there anything like agreement among all observers as to sex or other characteristics. Rüpzóiyăt was reported as a young man by all observers; Bŏp'pŭm was said to be a tall, fat or large man by six observers (Bottom was associated, however); five thought $Z \tilde{e}^{\prime}$ thẽ must be a girl; six reported Grĭb as a small man; and five reported Kird'faumish as a strong or big man. For all the remainder there was disagreement.

In the picture series, as a rule, three factors were operative in furnishing names: (I) similarity to some known person, (2) similarity to a type or class already named in literature or on the stage, and (3) symbolization of some trait of character or appearance (Mr. Fop, Mr. Glum). Only one of the seven observers consistently invented names that by sound were intended to fit the individual. In this case, however, as in others in both of the experiments, the attempt was frequently made to find a name or a person that was fitting in character as well as in appearance, or even aside from appearance. Observers who are poor visualizers and who at the same time have a 'feeling' for names often tend to typify some trait of character rather than some bodily trait. The two may coincide (fat and good nature); but it is obvious that such coincidence is not necessary.

It seems, then, that the physiognomy of a proper name is at best but one-and that not an important-factor out of the many which determine what personality shall be attached to the name. Authors, no doubt, choose names to 'fit' their characters. We know that Dickens came to Chuzzlewit through Sweezleden, Sweezleback, Sweezlewag, Chuzzletoe, Chuzzleboy, Chubblewig, and Chuzzlewig. The name was significant to him; and yet there were various types of Chuzzlewit, as there were various types of Nickleby. Indeed, the applicability of a surname to all the members of a family must, one would suppose, tend to prevent our attaching any special import to the name's physiognomy. As to Pickwick, Dickens did not create the name; he took it from a real person. It is worth noting, perhaps, that Seymour's first sketch "was of a long, thin man;" and that the change to the familiar figure came by way of a suggestion of Chapman's, the suggestion "of a friend of mine at Richmond, a fat old beau who would wear drab tights and black gaiters. His name was John Foster." 3 Here is complexity enough! Further, the "short and sonorous" name Bouvard is not that of a "slender and active person;" Bouvard is heavy, and Pécuchet is slight; the names -when one knows them-fit excellently, but they fit against Claparède's rule.

${ }^{3} \mathrm{~J}$. Forster. The Life of Charles Dickens, i., 1872, 88, 91 ; ii., $1873,23$. 
We conclude that the psychological response to unknown proper names is extremely variable. It depends not only upon imaginal type, but also upon associative and attitudinal factors which differ widely in individual observers. At the one extreme, the proper name is merely a word among words; at the other it is, as a proper name, richly suggestive. On the affective side, too, there is wide variation of response, from complete indifference to strongly emotional empathy. Moreover, a highly responsive observer is not uniformly responsive; certain names will 'leave him quite cold.'

We hope to continue this Study (I) by a detailed account of the reactions of certain highly responsive observers, and (2) by a psychological examination of the proper names employed by certain writers of fiction. 